\title{
Transing and Transpassing Across Sex-Gender Walls in Iran
}

\section{Citation}

Najmabadi, Afsaneh. 2008. Transing and Transpassing Across Sex-Gender Walls in Iran. Women's Studies Quarterly 36(3-4): 23-42.

\section{Published Version}

http://dx.doi.org/10.1353/wsq.0.0117

\section{Permanent link}

http://nrs.harvard.edu/urn-3:HUL.InstRepos:2450776

\section{Terms of Use}

This article was downloaded from Harvard University's DASH repository, and is made available under the terms and conditions applicable to Open Access Policy Articles, as set forth at http:// nrs.harvard.edu/urn-3:HUL.InstRepos:dash.current.terms-of-use\#OAP

\section{Share Your Story}

The Harvard community has made this article openly available.

Please share how this access benefits you. Submit a story.

Accessibility 
Transing and Transpassing Across Sex-Gender Walls in Iran

Afsaneh Najmabadi

\section{$\underline{\text { Introduction }}$}

Something happened in 2003-04: transsexuals and transsexuality in Iran suddenly became a hot media topic, both in Iran and internationally.

The medical practice of sex-change by means of surgery and hormones dates to at least the early 1970s in Iran; for nearly three decades the topic had received occasional coverage in the Iranian press, including a series of reports (presumably based on real lives) published in a popular magazine, Rah-i zindigi [Path of Life], beginning in 1999. $<1>$ Iranian press coverage of "trans" phenomena increased sharply in early 2003, however, and it has continued intensely ever since — sometimes reporting directly on transsexuals and transsexuality, and sometimes reporting on it in the context of other people marked as "vulnerable to social harm," such as prostitutes (both male and female) and runaway girls, who reportedly live trans-dressed lives. It was these latter two topics that drew the attention of documentary filmmaker Mitra Farahani, to the subject of transsexuals in Iran. Her documentary Just a Woman won international acclaim at the 2002 Berlin Gay and Lesbian Film Festival and elsewhere, and seems to have ignited broader international attention to the issue of transsexuality in Iran. A flurry of articles appeared in the world press in 2004-05. The Guardian, for example, wrote on 27 July 2005 that "today, the Islamic Republic of Iran occupies the unlikely role of global leader for sex change," and noted that "Iran has even become a magnet for patients from eastern 
European and Arab countries seeking to change their genders." A number of television documentaries in France, Sweden, Holland and the United Kingdom followed, as well as several independent documentary film productions (Abdo 2000; Fahti 2004; Eqbali 2004; McDowall and Khan 2004; Harrison 2005; Stack 2005; Tait 2005).

The celebratory tone of many of these reports-welcoming recognition of transsexuality and the permissibility of sex-change operations - is sometimes mixed with an element of surprise: How could this be happening in an Islamic state? In other accounts, the sanctioning of transsexuality is tightly framed by comparisons with punishments for sodomy and the presumed illegality of homosexuality—echoing, as we shall see, some of the official thinking in Iran. $<2>$

While transsexual surgeries are not new in Iran, over the past decade such operations seem to have increased not only in publicity, but also in actual frequency. At the first national symposium on transsexuality, "Studying Gender Identity Disorder," held in the northeastern provincial capital of Mashhad in May 2005, Dr. Kahani from the national Legal Medical Board reported that in the fifteen years between 1987 and 2001, 200 males and 70 females had submitted sex-change petitions to the Board, 214 of which had been approved. Over the next four years, between 2001 and 2004, another 200 petitions had been received. $<3>$ Anecdotal statistics from a private sex-change clinic in Tehran point to similar increases - for the period 1985-1995, 125 of 153 clients went through partial or full sex-change operations; in the next decade, the numbers increased to 200 surgeries in a client population of 210 . 
The increasing frequency of sex-change petitions and operations is not an unproblematically positive development, empowering though this trend has been for transsexuals. Many political challenges are posed by framing transsexuality within a dominant mapping of sexuality that explicitly renders as diseased, abnormal, deviant and at times criminal any sexual or gender non-conformity (including transsexuality itself, as well as same-sex desires and practices). For legal and medical authorities, sex-change surgeries are explicitly framed as the cure for a diseased abnormality, and on occasion they are proposed as a religio-legally sanctioned option for heteronormalizing people with same-sex desires or practices. Even though this possible option has not become state policy (because official discourse is also invested in making an essential distinction between transsexuals and homosexuals), recent international media coverage of transsexuality in Iran increasingly emphasizes the possibility that sex-reassignment surgery (SRS) is being performed coercively on Iranian homosexuals by a fundamentalist Islamic government (Ireland 2007). This narrative framing (along with similar ones concerning the suppression of women's rights and other political and labor struggles) circulates within larger reductive and totalizing Euro-American discourses on Iran and Islam that equate them both with the most conservative factions of the Iranian government, and with the views of the most fundamentalist Islamists. Conservative forces in both Iran and the West have a common stake in ignoring the lively reform discourse and history of progressive activism within contemporary Iran that offers alternative notions of rights within an Islamic society, and of alternative modes of living a Muslim life. 
While the pressures on gays and lesbians in Iran to transition from one gender to another are very real, these pressures are not produced primarily by fear of criminality. $<4>$ On the contrary: the religio-legal framework of transsexuality has been productive of paradoxical, and certainly unintended, effects that at times benefit homosexuals. Simply put, the religio-legal prohibition of same-sex practices does contribute to pressures on gays and lesbians to consider transsexuality as a religiously sanctioned legal alternative (which is particularly important for religiously observant persons), but instead of eliminating same-sex desires and practices, it has actually provided more room for relatively safer semi-public gay and lesbian social space, and for less conflicted selfperceptions among people with same-sex desires and practices. As one pre-op FtM (female-to-male transsexual) succinctly put it: "Once I was diagnosed as TS, I started having sex with my girl-friend without feeling guilty."

\section{A Brief History of Transsexuality in Iran}

Some of the earliest discussions in Iran of transgenderism and transsexuality appeared in the 1940s, within a body of popular marital and parental advice literature translated into Persian (largely from American popular psychology authors) in which discussions of love, desire, sex, and marriage supplied occasions to write about gender disidentification, homosexuality, intersex conditions, and sex-change. (Some of the earliest discussions of transgenderism and transsexuality in Europe and the U.S. appeared in these very same sources). $<5>$ Surgeries to alter congenital intersex conditions were reported in the Iranian press as early as 1930 (Ittila'at, 27 October 1930), and the intensification of 
reporting on these surgeries in the 1940s and '50s forms an important backdrop to the subsequent history of transsexuality in Iran. By the late 1960s, notions of "gender disorder" and hormonal or genetic "sex and gender determination" began to enter Iranian medical discourse via translated behavioral psychology books and medical texts. The earliest non-intersex sex-change surgery reported in the Iranian press (that I have found so far) dates to February 1973 (Kayhan, 17 February 1973), and by the early 1970s, at least one hospital in Tehran and one in Shiraz were carrying out SRS. A 1976 report by Dr. Kariminizhad of Jahanshah Saleh Women's Hospital stated that over the previous three years, some fifty persons with transsexual tendencies had been seen at the hospital, and that 20 of them had gone through SRS (Kayhan, 11 October 1976.) Around the same time, the Medical Association of Iran (MAI), a professional state-affiliated organization of physicians, began discussing the medical ethics of surgical sex-change. In a 1976 decision, the MAI declared that sex-change operations, except in intersex cases, were ethically unacceptable - a ruling that was not reversed for more than a decade.

As early as 1967, Ayatollah Khomeini had published a fatwa sanctioning sex-change, but this ruling, issued by a dissident Khomeini then still living in exile in Iraq, did not influence the policies of legal or medical institutions in Iran. (Khomeini 1967, Vol. 2: 753-755.) There is no unanimity of opinion among leading clerics in Iran on the issue transsexuality. Numerically speaking, the majority of opinion-issuing clerics consider only intersex surgeries to be acceptable unequivocally. The opinion that ultimately matters, however, is that of the cleric(s) in political power, regardless of relative religious authority. The historically specific relationship between jurisprudential and political 
authority that has characterized Iran since the early 1980s translates clerical opinion, sanctioned through a complex legal process, into the law. With Ayatollah Khomeini as a politically unchallenged supreme authority after the 1979 revolution until his death in 1989, the reissuance in 1985 of his 1967 fatwa on SRS, in Persian this time rather than Arabic, set in motion the process that culminated in new state-sanctioned medico-legal procedures regarding transsexuality. $<6>$

From the earliest pronouncement to present-day opinions, reflections on transsexual surgery in Iran seem to have been informed in part by linking these bodily changes to similar questions posed about intersex bodies. Classical Islamic discourse categorized every human body as either male or female, yet accepted the possibility that in the case of hermaphrodites it was difficult and at times impossible to determine the body's "true genus" (kind or type). $<7>$ Jurisprudents then elaborated rules of behavior to deal with the possible threat of gender transgressions that such impossibility of knowing would produce (Sanders 1991). In its modern reconfiguration, jurisprudents argued that new medical sciences could help unravel the puzzle of proper genus in difficult cases of hermaphroditism, and that medical technology could correct the manifestation of that genus.

Importantly, by the 1960s, the approval of medicalized means for manifesting the proper genus of the hermaphroditic body converged with, and eventually (in the post-1979 period) acted as, religious sanction for the emerging medico-psycho-behavioral discourse on gender and sexual dimorphism. Not only did the true sex become knowable in spite of 
ambiguous genitalia; a determinate relation among gender identification, gender role behavior, sexual desire, and subjective gender identity was envisioned for each and every body. The convergence of these discourses consolidated a powerful religio-legal-psychomedical notion of "unnatural and deviant" sexualities that now circulates in the Iranian national press, in religious texts, in bio-medical and psychological writings, and in marital and parental advice literature. With the establishment and consolidation of the Islamic Republic in the 1980s, this discourse gained state support, finance, and force of law, providing the conditions of possibility for transsexuality in Iran on a new scale, while setting the contours within which transsexuals fight their battles and live their lives, often with imaginative successes, and at other times with frustration and terrible loss.

The "trans-friendly" jurisprudential discourse on transsexuality that began as an elaboration on intersex discourse now approves of transsexuality on the discretionary grounds that it has not been specifically forbidden in the Qur'an. Invoking a distinction between the physical body and the soul, this discourse argues that in most people there is harmony between the two, but that in a small number of people a disharmony produces transsexuality; since we cannot change a person's soul, but medical advances have made it possible to change a person's body, transsexual surgery is a permissible solution to this disharmony between soul and body. As a discretionary matter, SRS is not required-nor even recommended - for a person diagnosed as transsexual, unless a religiously observant transsexual fears falling into sinful deeds. $<8>$ Some of the more accepting people among the friends and kin of transsexuals have come to terms with transsexuality through understanding it as a "wonder of creation," or sign of God's power. Some trans- 
friendly and gay-friendly psychotherapists use the same language in working with families. While this may sound to many of us terribly "essentialist," I have come to hear it as an alternatively enabling script, especially as compared to the more dominant (and no less essentialist) psycho-medical discourse.

Public knowledge of transsexuality has been shaped not only by jurisprudential and biomedical discourses, but also by intensive coverage in the Iranian press (and to some extent by satellite television broadcasts). In addition to the previously mentioned reports

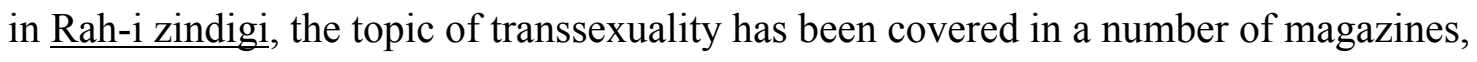
such as Zanan, and Chilchiraq, and important dailies, such as I'timad-i melli, I'timad,

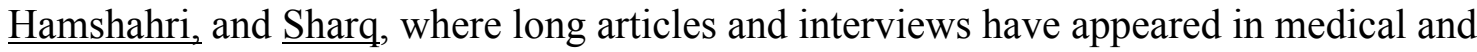
science sections. The "yellow press" also covers transsexuality, and for a brief period in 2004-05 gave the topic frequent full-page coverage, sometimes featuring translated articles that had appeared in the international press. This sustained coverage, despite the lean quality of the content - sometimes repeating the same story in various issues of the same journal—has made transsexuality one of the stock attention-grabbing stories for the scandal sheets, along with stories about film stars' lives, and various sexual and social scandals. The combination of kinds of coverage - with the dailies and science journals making transsexuality a respectable topic of social conversation, and the sensational press bringing it into popular knowledge — has made transsexuality a widely recognized topic, though by no means a generally approved-of one. It is possible that the increased frequency of SRS in the past decade has been enabled by this expansion of public discourse. Many transsexuals I listened to, especially those coming to Tehran from 
provincial towns, said they had found out about SRS clinics through the press coverage (including satellite broadcast of documentaries).

What kind of subjectivity is afforded to transsexuals through their public recognition as strange creations or scandalously diseased bodies, and how do transsexuals themselves respond to these representations? Some of the intimate details of transsexuals' lives reported in the tabloids would be unimaginable if the subjects were recognized as "normal heterosexuals." It is only as transsexuals that their sexual lives become printable stories. What effects do this possibility of scandalous or "strange" public intimacy generate for conceptions of gender and sexuality more generally—especially given that the scandal sheets, like the rest of the press, have to be wary of violating the restrictions of the Ministry of Islamic Guidance? As Dupret and Ferrié have written of Egypt and Morocco, what happens when claims for certain intimate lives become possible largely through "publicizing the private," their regulation justified through their potential criminality? (Dupret 2001; Ferrié 1995) When the cover of the tabloid visually frames the headlines about transsexuals with headlines about murder, urban crimes, and cannibalism, what kind of empathy can even a sympathetic transsexual story generate, bordered as it is by stories designed to provoke urban panic and moral revulsion? $<9>$

\section{Venturing into Ethnography}

It was with these uneasy thoughts that I began my research in Iran in May 2006. Two questions formed my initial thinking: First, in a cultural-legal context where same-sex desire is considered shameful and same-sex practices are illegal, but within which 
transsexuality, even if overwhelmingly understood as shameful, is nevertheless legal and state-subsidized, how does this configuration shape sexual and gender subjectivities? Second, how do insistent state regulations and religio-cultural codes and rituals concerning proper gender conduct shape sexual desires and gender subjectivities? How does this context map the terrain on which individuals come to identify as TS and decide how far to go in their transitions?

For instance, the protocols of sex-change often involve a prolonged period of supervised transition, during which the person lives socially as the other gender. In Iran, I had imagined, this procedure would face difficulties because of a whole series of state regulations on gender segregation. How do people in transition, I wondered, how do they navigate gender regulations? Religious and state regulations aim to produce a sense of bodily appropriateness through daily observations of gendered homosocializing practices, whether at home (for religiously observant families), in streets and parks, or in offices and universities. What is the legally sanctified gender of a trans-dressed in-transition person, given that the public dress-code is so insistently gender-regulated? What might the "impossibility of living as the other gender" mean for the concepts and practices of sex-change? Despite my initial forebodings, my ethnographic research (the results of which are summarized in what follows) soon made it clear to me that the explicit framing of transsexuality as linked with, and yet distinct from, homosexuality and other sexualities rendered deviant and sometimes criminal, has produced some highly paradoxical effects. 
The typical autobiographical narrative, as well as the diagnostic psychological symptomization and the supervised process of legal certification of transsexuality, have all keyed themselves to the distinction established between transsexuality and homosexuality. A typical autobiographical narrative begins with the familiar recounting of a childhood in which the subject did not wish to dress and play gender-appropriately. Popular parental advice psychology literature now routinely warns parents about such early symptoms. Parents are advised to not encourage such childhood tendencies by thinking of cross-gender behavior as cute; they are told to consult child psychologists to get help in dealing with this "problem" as early as possible, to prevent the "full blown stage" of adult transsexuality.

In the dominant narrative of the transsexual life-course, a cross-gendered childhood usually leads to a troubled adolescence in which same-sex desires torment the subject, especially given that all schools in Iran are gender-segregated. The strong relationship between childhood "transgender symptoms" and adolescent "sexual symptoms" signals the many ways in which gender and sex are not taken to be distinct categories in all registers in Iran. Indeed, in some registers, lives are made possible through that very indistinction - as in the case of certified non-operated transsexuals who would become illegal subjects should "transgender" (i.e., non-medicalized cross-gender living) become widely accepted as distinct from transsexual.

Transsexuals who profess religious beliefs usually emphasize that they had not engaged in any same-sex acts despite persistent desires. Others hint at same-sex activities as a 
further corroboration of their transsexuality. Both groups tend to recite a series of school troubles, leading to parents being informed that their child has "problems," referrals to psychologists, possibly dropping out of school or being expelled if suspected of improper sexual activities. These troubled years begin the long process toward eventual gender transition.

Often this is the beginning of long family battles. Parents resort to sometimes horrifying measures to dissuade their adolescent teenagers from their contrarian sexual/gender desires. Some transsexuals succeed in hiding their sexual/gender desires from parents and improvise their own livable patterns. Even post-op, some live complicated multiple lives to be able to stay connected to their families. They leave home dressed as one gender, then change to the other. This strategy is easier for FtMs who can just take off their outer covers, than for MtFs who must not only adjust clothes, but also apply make-up under bridges, in garages, in public toilets in parks, and other available public spaces--all of which are potentially dangerous for them, with regular reports of MtF transsexuals who have been attacked and occasionally murdered in such locations.

Adolescents sent by school authorities or concerned parents for help from therapists and physicians are sometimes diagnosed as "afflicted by GID," and often find themselves thrown into a combative situation with therapists who decide to cure them of these wrong gender/sexual desires. The latter include both mainstream psychologists as well as a vocal group of psychotherapists who advocate and practice Islam-therapy (sometimes called spiritual therapy). Adolescence is the period in which many transsexuals, 
especially MtFs, find family life either unbearable and leave, at least temporarily, or are thrown out by families. Family severance is a very serious social issue, as so much of one's life is defined and made possible (or impossible) through one's location within an intricate network of extended family members, family friends, and acquaintances. Thus, severance from family often means not only emotional hardship and homelessness for prospective transsexuals, but also a loss of education and job opportunities. While transsexuals tend to find each other and form alternative kin worlds of their own, they often face enormous problems in the immediate period of being thrown out into a hostile world. MtFs are much more likely to face this predicament than FtMs. Correspondingly, family reconciliation is often easier for FtMs than MtFs. Several close relatives of (pre/non/post-op) FtMs explicitly said their acceptance of their daughter/sister becoming a son/brother would have been unimaginable if it had been the other way around.

The reason for this disparity is not simply gender bias, though it is that too-namely, the preference for a male off-spring. More importantly, the disparity arises from the repugnance and shame that the culture associates with "passive" male same-sex practices. MtFs seem, sadly and ironically, to live forever under the sign of being kunis (literally meaning "anal," but in Persian connoting receptive of anal penetration), even though that is precisely what in many cases they are trying to disavow and move away from through sex-change. $<10>$ In their autobiographical narratives, many reiterate that they have never allowed themselves to be anally penetrated even with their long-time boyfriends, and that they have been patiently going through the legal and medical changes in order to acquire a vagina before they get married. Yet, their physiological changes and their 
insistent self-narrativizations notwithstanding, they continue to carry the burden of that stigmatization with them even post-operatively. For their families, they remain a life-long source of shame among their kin and neighborhood networks. Even families that have not reconciled with their offspring "lost" to sex-change sometimes move to a new neighborhood or town in order to live again without shame. The insistence of many transsexuals to distinguish themselves individually and as a group from homosexuals is thus not simply because of the religio-legal status of transsexuality, and their need to protect themselves from charges of homosexuality; this attempted disarticulation nevertheless carries with it, and participates in regenerating, a sign of stigmatization. It is a delineating move that in fact reinforces a burden they cannot shed.

\section{Filtering}

The legal process of gender transition is firmly framed by the pivotal distinction between homosexuality and transsexuality. Colloquially referred to as "filtering," legal gendertransitioning involves a four-to-six month course of psychotherapy, accompanied by hormonal and chromosomal tests. It aims to distinguish and segregate "true transsexuals" (for whom any same-sex desire and even hints of same-sex practices are considered symptomatic of their transsexuality) from misguided or opportunist homosexuals (whose same-sex desires and practices are viewed as signs of moral deviancy) seeking to avoid anti-homosexual censure. $<11>$ In the worst cases, filtering establishes a very hostile and at times terrifying relationship between the therapist and the client. This is particularly the case with those therapists who practice Islam-therapy. Several transsexuals recounted contemplating or attempting suicide during the filtering process. Other therapists, 
however, actually have used filtering to support their gay and lesbian clients, and to form separate individual and group sessions for them, thereby providing important social venues.

As I have already hinted, the very process of psychological filtering and jurisprudential wall-building between gender and sexual categories, far from eliminating gays and lesbians (if that is indeed what the authorities hope for), paradoxically has created new social spaces. Instead of constructing an impassable border, the process has generated a porously marked, nebulous, and spacious domain populated by a variety of "not-normal" people. In order to persuade some gays and lesbians ("symptomatic homosexuals") to consider transing bodily, and to filter out the true ("morally deviant") homosexuals, this process needs to offer a safe passage between categories. As the filtering and sorting processes depend above all on individual self-narratives, the potential uses of this "nebula" are limited only by each involved person's creativity—a decidedly abundant resource.

As a wise friend urged me back in 2005, before I began my field research, "Don't worry, people are very creative and make their own uses.” And this is what I have in fact learned: not to underestimate the real problems and challenges, and at times dangers, that transsexuals, gays, and lesbians face in Iran, but also to see the productivity (in a Foucauldian sense) of the power of legal-medical-religious regulations, as well as the creativity with which transsexuals, gays, and lesbians use the spaces such regulative 
power provides, and the ways in which their active participation and struggles change things.

Here is where refusing a distinction between sex and gender has been very productive. One can live what we may name a transgendered life (that is, non-operated yet sex/gender discordant) as a certified transsexual. This is perfectly legal and religiously permissible. As one trans-friendly cleric, Hujjat al-Islam Kariminia, agreed in the course of our many conversations and written communications, physiological transitioning is something that is allowed but not required. This means that a certified transsexual can, but does not have to, take hormones or go for surgery. S/he can legally live as the other gender. While legal and religious officials do not like this, they cannot do much about it. They are not being lenient and tolerant; rather, the very mechanisms of their project to filter and sort homosexuals from transsexuals depends on turning a blind eye on the "space of passing" across the very walls they have tried to erect.

Indeed, one doesn't even have to engage with the filtering process to be able to speak, at least in some spaces, as openly gay. In official circumstances, homosexually-oriented persons, with or sometimes without certification as transsexual, refer to themselves in a variety of ways. For example, one man who, in a safer space, self-identified as gay, would say in a weekly TS group session held at the Social Emergency Unit of Welfare Organization, "I am not sure what I am, maybe I am gay, maybe I am TS, I am here to find out.” In the 2005 Mashhad seminar on gender identity disorder, an MtF-looking person from the audience asked Hujjat al-Islam Kariminia about rules for certain 
religious observances for "those of us who are bilataklif [undecided, ambivalent, in a conundrum]. Do we enter the Imam Riza Shrine through the men's entrance or the women's?" Hujjat al-Islam Kariminia's response was very telling: "You should go through the entrance that is appropriate for how you are dressed." This would, of course, not resolve their actual dilemma, in contrast to their hypothetical jurisprudential one; for upon entering the apparently-gender-appropriate entrance, one is subjected to bodily security searches which would result in serious trouble for a TS. Yet Kariminia's answer itself was what astonished me, because in a conversation in his office in Qum, in response to my suggestion that transsexuals should be allowed to live as transgender and not necessarily be pushed to hormonal and surgical treatment, he had insisted that the anatomical body defined maleness or females in Islam. In a later conversation, however, he agreed that certified transsexuals could trans-dress, and in a written communication he confirmed that they could even live as the other gender in all ways except for having sex with someone of their own bodily sex. Clearly, the context of asking made for different responses, as anyone familiar with the tradition of Islamic (or Jewish) responsa literature would immediately recognize.

The legal and religious authorities, in short, have a stake in keeping open the nebulous domains of passing, even as they try to clear them of any "opportunistic squatters" and keep their population under surveillance. $<12>$ The passageways across the porous boundaries between homosexuals and transsexuals at times fuels the hostility of some MtFs (especially those who are post-op) towards gay men. In keeping with general social attitudes, they consider gay men to be shamefully anally receptive, and suspect them to 
be actual or potential sex workers and HIV-carriers; "They give us all a bad name" was an oft-repeated phrase. Despite all these challenges, however, these passages ought to remain open.

\section{Alternative Alliances}

Recently, an alternative alliance has emerged between some MtF transsexuals and gay men. $<13>$ They argue that they share much in common as people who differ from social norms and expectations, and that the state-regulated filtering process should not become a hostile division among them. In 2006, one transsexual group began to welcome gays and lesbians to its weekly meetings. $<14>$ These emerging openings and alliances have begun to create conditions for re-thinking and re-appropriating dominant cultural concepts. In the TS meeting held in the Welfare Organization, a gay man argued before a governmentappointed social worker that since the culture named them all as deviants, those who were thus labeled therefore possessed the power to redefine what that label might mean. Think metaphorically of driving, he argued that most people take the straight highway to get where they want to go, but gays, lesbians, and transsexuals deviate from the straight path and take some side roads - a much more interesting way to travel than the boring straight highway. Even within such relatively open and hospitable spaces, however, the overall social stigmatization of gay men and transsexual women produces enormous pressure to police each other's lives. The public appearance of MtFs, many of whom often display their femininity by "excessive" styles of clothes and make-up, in a social context where female public visibility is heavily scrutinized, is a continuous subject of 
approbation by others. MtFs who are even rumored to engage in sex-work are a continuous target of harsh criticism.

I do not wish to deny the enormous pressures on gays and lesbians to physically transition, which some gays and lesbians do consider in order to make their lives more livable. Their decision to transition derives not merely from religious sanctions nor as a result of enforcing laws against same-sex practices. It cannot be dismissed simply as a "false recognition" achieved under therapeutic duress, nor incited by the media (as in the formula, "I read an article or saw a TV program and now realize I am TS"). Nor does it represent a "lack of imagination," as one diasporic self-identified queer Iranian once put it to me. Such moments of medico-psychological diagnosis or self-recognition are occasioned by larger social and cultural patterns of gender and sexual life, in particular the pressure to marry and form families. They are informed by all the simple pleasures of daily life from which same-sex partners are excluded; as one such woman said, "We can't be together at Nawruz [Persian new year]; each of us has to be with her family. We start every new year in separation."

The social expectation for every adult to get married, later if not sooner, affects sexual and gender relations in important ways. While there has been a great deal more open premarital sexual experimentation (including same-sex activities) among adolescents and young adults in recent years, these remain just that: pre-marital. Male-male and femalefemale couples live under, and compete with, the severe threat of the marriage demand. At times, "passive" males overact their femininity in a desperate attempt to avert the 
threat of a "real" woman and the loss of their male partner to marriage. The same is true of female-female couples: there are abundant sad narratives of long-term lesbian relations breaking apart because the "femme" partner finally opted for marrying a "real" man (or finally gave in to familial and social expectations to do so), in spite of the heroic butch performance of her former lover. This same pressure for marriage informs the dominant culture's deep investment in the performance of masculinity and femininity, and partially accounts for heavily gender-coded roles within same-sex partnerships. This, perhaps even more than the illegality of same-sex practices and the legality of transsexuality, pushes some people who may otherwise define themselves as butch lesbians and effeminate gays towards transing. They expect transing to make marriage available to them and, in a few instances, to salvage a threatened same-sex relation. Nevertheless, relationships involving transsexuals still always exist under the threat of inauthenticity. Post-op transsexuals, even though they have aspired to be bodily like the other sex, are often dismissed as "plastic replicas," and social pressures sometimes lead the partners to contemplate leaving a "fake" man or woman for a "real" one-as many post-op break-up stories reiterate and repeat. Despite the circulation of such sad stories, the larger social pressures for marriage continue to push some people in the transsexual direction.

\section{Conclusion}

Having provisionally mapped some configurations of sexuality and gender in contemporary Iran, I will conclude with a few questions that may be of interest for transnational comparison. What does it mean that concepts of gender, sex, and sexuality - along with their (in)distinction from, and relations to, one another-have been 
formed in a context that has not been shaped to any substantial degree by the identity politics of gender and sexuality, or by queer activism and queer critical theory? Some of the distinctions between these categories within Euro-American contexts, including the distinction sometimes made between transgender/transsexual (based on the body that has been surgically modified), have been shaped over the past couple of decades by a particular set of political struggles and debates. How do seemingly similar assignations mean differently (or not) within a different politics of sex, sexuality, and gender? While identity struggles have raged within transnational diasporic Iranian communities, many gays, lesbians, and transsexuals in Iran wish to keep national and international politics out of their daily lives. Indeed, some have become quite wary of international coverage of transsexuality in Iran, feeling that the effects of such coverage, within this volatile scene of meaning-making, is beyond their control. Despite their aversion to the international politics of human and civil rights for sexual and gender identities, some of these global discussions have nevertheless reached Iran through web-logs, satellite TV broadcasts, and other transnational media. Loan-words such as straight, gay, lesbian, transsexual, homosexual, top, bottom, and versatile, among many other expressions, pronounced in Persian just as they are in English, are freely used in these discussions. How do these enunciations mean differently, and do a different cultural work, in Tehran compared to New York? Perhaps, one of the problems with the current heated debates between proponents of "global gay" and opponents of "gay international" resides in their common presumption that "I am gay," or that "I am transsexual," means the same thing anywhere it is pronounced. $<15>$ 


\section{Acknowledgement}

This essay has been enabled through numerous conversations with transsexuals, gays, and lesbians in several cities in Iran during 2006-07. It has also taken shape through discussions after its presentation at several campuses: Tehran University, Barnard College, Harvard School of Public Health, University of Connecticut, Princeton University, University of Washington, University of Illinois, several campuses affiliated with the Greater Philadelphia Women's Studies Consortium, University of Pittsburgh, Yale University, University of Delaware, Stanford University, University of California (Berkeley), Harvard University (Center for Middle Eastern Studies), Simon Fraser University, Dalhousie University, Wellesley College, and Williams College. I am deeply indebted and grateful to all the people involved, but as at present I cannot thank the first group by name, I opted for skipping all names; except for Susan Stryker whose critical feedback and skillful editing transformed a very raw essay into a more readable text.

Afsaneh Najmabadi teaches History and Studies of Women, Gender, and Sexuality at Harvard University. Her last book, Women with Mustaches and Men without Beards: Gender and Sexual Anxieties of Iranian Modernity (Berkeley: University of California Press, 2005), received the 2005 Joan Kelly Memorial Prize from the American Historical Association. She is currently working on Sex in Change: Configurations of Sexuality and Gender in Contemporary Iran, and Genus of Sex: How Jins Became Sex.

Notes 
1. These reports ran from 4 February 1999 to 5 January 2000. The same journal ran another series of autobiographical essays from 22 November 2003 to 22 November 2005. This body of writing constitutes the most extensive published transsexual narratives we have.

2. I say "presumed illegality of homosexuality," because what is a punishable offense is sexual acts between members of the same sex, with anal penetration of one man by another (liwat/sodomy) being a capital offense. In international coverage, liwat is almost always translated as homosexuality. The problem with this translation is that such reports find their way back into Persian, and in their Persian effects they converge with the medical and psychological discourses in which the dominant concepts are sexual orientation and typologies of desire, centered on the naturalness of heterosexuality. In that domain, instead of the legal-jurisprudential category of sodomy, it is homosexuality [rendered in Persian as hamjisgara'i, being inclined to a person of one's own sex] that is discussed as a sexual deviation along with a whole gamut of other deviations. While most theologically trained persons use liwat, more often than not, professionals (social workers, surgeons, and therapists) use hamjisgara' $i$. It is this slippage between the two concepts in different registers that are increasingly crossing paths -- especially within various state institutions that deal with transsexuals-transgenders and with some individuals who do name themselves gay or lesbian -- that makes me cautious about a simple usage of this term. I am concerned about keeping this distinction because in conversations in Iran it became quite clear that this is a productive distinction for many Iranian gays and lesbians, who find a degree of safety in insisting that homosexuality is 
not illegal, providing them with a sense of possibility of testing public spaces where some indication of their sexual desires (keeping it clear of what sex they do) may be a worthy risk. When I quote from English documentary sources, I have no way of knowing which term had been used in Persian, except in case of documentaries that have Persian sound track.

3. Shakhis, 24 May 2005. More recently, the Welfare Organization reported that it received three new TS applications a day. Other reports estimate the total number of transsexuals in Iran anywhere between 3000 to 5000, and sometimes as high as 25,000. My use of TS in this article is occasioned by its usage as a self-identification category among Iranian transsexuals. It is used in Persian pronounced ti-es.

4. I realize this is a controversial claim, since much of the current coverage of transsexuality in Iran claims otherwise. My conclusions in this paper are based on fieldwork in Iran over 2006-07 which is impossible to present at any length within the scope of an article. While transsexuals, gays, and lesbians whom I listened to over that period expressed many anxieties, fears, desires, and dreams, none was related to anything that was linked with fear of criminality. The issue of criminality is of course not trivial: criminality, and in particular capital punishment of sodomy, dynamizes many other legal restrictions and social fears.

5. Among them: Christian Jorgensen, Elizabeth Call, Vince Jones, Juliet (formerly Julius, no last name given in report), Robert Allen, Edwin Emerton, Roberta Cowell, Rollando 
Cassioti, April Ashley (formerly George Jameson), Gino Malti, Jeanette Jiousselot, and Phoebe Simple.

6. Favorable commentators often contrast Iran with other Muslim countries; the legality of certain medical technologies (not only SRS, but also a wide array of reproductive technologies) in the former and their illegality in some of the latter countries is narrated as if somehow linked with an ahistorical Shi`i-Sunni divide. This perpetuates such historically unsound arguments as the claim that the gate of ijtihad [issuing jurisprudential opinion] was closed in the Sunni world, thus making Shi'ism more open to change. While this argument may seem almost commonsensical (especially to many Shi'is), it misses the key issue of the historically specific relationship between jurisprudential and political authority that has characterized Iran since the early 1980s, which translates clerical opinion into the state's legal code.

7. I use the word genus for jins in this context to highlight the distinction between what today is commonly referred to as sex [jins] and the earlier connotations of the same term in classical Islamic writings on this topic - an issue further elaborated in Najmabadi 2008.

8. Despite my own earlier foreboding (Najmabadi 2005; see also my critical selfreflections on this piece in H-Net discussion. Posted on Sat, 19 May 2007, HHistsex@H-Net.msu.edu, Subject: Re: Reportage: Iran: Change Sex or Die), I know of 
no case in which a homosexual has been forced to change sex. Nor have I seen such evidence offered by commentators who claim punitive use of SRS for gays in Iran.

9. Some of my thinking here has been deeply influenced by conversations with Judith Surkis on her current research project, "Scandalous Subjects: Indecency and Public Order in France and French Algeria."

10. The entry into Persian and wide circulation of "gay" (pronounced as in English) and less frequently "lezbish" (lesbian butch) may indicate (contrary to the presumption of imitation of or imposition by the "Gay International" on unsuspecting naïve Iranians) in part an attempt to move away from the burden of the stigma that kuni (and to a lesser extent baruni, used for the "active" partner in a lesbian relationship) carries with it. In other words, to the extent that the adoption of gay and lesbian into Persian nomenclature can be viewed as some sort of mimicry, it is a strategic move to shed the cultural stigma of kuni (and baruni). Other Englishisms serve similar cultural effects, as the wide use of bi-ef $[\mathrm{BF}]$ and gi-ef $[\mathrm{GF}]$ for boyfriend and girlfriend. Whether these language moves work or fail is not determined because of the presumed shortcoming of "mimicry," nor because of the cultural power of domination by a presumed "gay international" that is exporting its identity categories in imperial fashion. Its potential source of trouble is the tight gender grid within which same-sex relationships in contemporary Iran are configured. This configuration is in turn an effect of the marriage imperative (see below) which shapes particular notions of masculine and feminine performance (within heterosexual relationships as well). Same-sex partners, however, are prone to "over- 
performance" because of dominant pressures and hazards of marginalized lives. In the context of South Asia, the adoption of such English words is sometimes seen as "a classspecific rejection of indigenous categories." See the thread Homosexual/gay/queer in June and July 2007 on H-Net Histsex. I am not convinced that such straight forward class delineations can be made.

11. The process includes a series of written tests for which translations of MMPI (Minnesota Multiphasic Personality Index) and SCL-90-R (Symptom Checklist-90-R) are used to make sure the TS is not suffering from other mental disorders, and if so, to be treated first for these problems to make sure the presumed line of causality runs from TS to other symptoms rather than the other way around. TSs prepare for these tests and coach each other for oral interviews, much as graduating high-school students in Iran prepare for the national entrance exam to universities. Oral interviews cover questions about details of life stories, but also totally idio(syncra)tic questions and gestures, such as checking what kind of watch the person is wearing, if they have shaven legs, color preferences, how they squeeze a toothpaste tube (from bottom up or from the middle), etc. When TSs were recounting these questions, their laugher expressed better than anything else the performativity of this procedure - something that the officials are fully aware of, including therapists I interviewed.

12. The legal and social scene is highly fluid as I write these lines. Some authorities try to tighten what they see as unfortunate loopholes; others in different ministries and state organizations have formed supportive working relations with TS activists and help them 
to neutralize or go around restrictions and get legal, medical, housing, and other material benefits. One of the challenges of my project, practically and analytically, is that over 29 years after the revolution, the Iranian state remains highly fractured, internally changing, and volatile. While a lot has been written on the fractured nature of the Iranian political system since the revolution of 1979, early in my research it became clear that thinking of the state even as a fractured mosaic of competing and at times conflicting mini pieces would not do; perhaps a better visual imaginary would be pieces that are continuously shifting and changing colors, with no well-defined edges of any sort. How such a structure does not burst at the mobile junctions of these shifting pieces, how it does its stately work so-to-speak, is a question I put aside for now. This situation allows transsexuals (and other activists) to cultivate their own horizontal and vertical networks in and out of various governmental bodies that do not fit neat categorizations as governmental and non-governmental. While permitting a vast degree of creativity, it also makes their work highly susceptible to the ebbs and flows of rapid political changes that mark the country. Several trans-rights activists have emerged from the transsexual community over the past four or five years, and the current changes are above all their achievements. Their efforts to challenge and change the medical, legal, and police abuses that transsexuals and gay men (and to a much lesser extent lesbians, for a complicated set of reasons) face are very impressive. They go to various government bodies on an almost daily basis and lobby for their rights and the benefits they expect the government to provide for them. There are often setbacks. The legal hoops that they are often made to go through are mind-boggling, and it is a testament to their fighting spirit and their sense of citizenship that they continue their work. One major issue is the understandable desire 
of many post-op transsexuals to become "invisible" and live "normal lives." This has meant a huge turnover of activists, and the loss of continuity and organizational experience. The legal process, and the existence of some social welfare support for transsexuals, does not of course mean transsexuals are not targets of threats, harassments, and arrests by police and paramilitary forces_- but these attacks do not have a uniform pattern. There are highs and lows. In this, the transsexual community's situation is not different from others who cross various "red lines" in Iran. Whether the attacks on gays and transsexuals are more severe than on other groups, or on other moral or political grounds, I do not know. I don't know of any study that has actually brought together all the rape, adultery, and sexuality-charged trials and figured out if there is a pattern. I don't know of anyone who has systematically studied the attacks on workers and students rights activists, women's rights activists, journalists, political dissidents, and those on more ordinary daily ones, such as arrests of women on charges of bad-veiling and assaults on parties, with those of gays and gay parties, to know if there is a difference.

13. Lesbians are largely absent from this scene. There seems to be a pattern in which f-f sexual and affective relationships and socializing networks take shape largely in nonpublicly-visible spaces.

14. This was opposed by other MtFs and became a subject of much debate. The group subsequently had to cease its meetings, because the magazine in whose office the meetings were held was closed down. The magazine itself had been charged with 
crossing "red-lines" in its coverage of explicitly sexual topics in the language of psychology.

15. Altman's Global Sex (2001) as well as Massad's Desiring Arabs (2007) and his 2002 article are perhaps the most polarized points of this debate. Publication of these writings has generated a much larger conversation, especially among scholars and activists concerned with issues of sexuality in non-Euro-American cultures. See Rofel (2007) for example.

\section{Works Cited}

Abdo, Geneive. 2000. "Sex-change Iranian Hates Life as Woman." The Guardian, June 20, World News section.

Altman, Dennis. 2001. Global Sex. Chicago: The University of Chicago Press.

Dupret, B. 2001. "Sexual Morality at the Egyptian Bar: Female Circumcision, Sex Change Operations, and Motives for Suing," Islamic Law and Society 9(1):42-69.

Eqbali, Aresu. 2004. "Iran's Transsexuals Get Islamic Approval, But!” Middle East Online, September 30, http://www.middle-east-online.com/english/?id=11423.

Fathi, Nazila. 2004. "As Repression Eases, More Iranians Change their Sex." New York Times, August 2, World section.

Ferrié, J. N. 1995. "Lieux intérieurs et culture publique au Maroc," Politix 31:187-202.

Harrison, Frances. 2005. "Iran's sex-change operation,” BBC Newsnight, January, http://news.bbc.co.uk/1/hi/programmes/newsnight/4115535.stm.

Ireland, Doug. "Change Sex or Die."

http://direland.typepad.com/direland/2007/05/change_sex_or_d.html. 
Khomeini, Ruhallah. 1967 (or 1968 -- 1387AH)_Tahrir al-wasila. Najaf: Matba'at alAdab.

Massad, Joseph. 2007. Desiring Arabs. Chicago: The University of Chicago Press.

Massad, Joseph. 2002. "Re-Orienting Desire: The Gay International and the Arab World." Public Culture, 14(2):361-385.

McDowall, Angus and Stephen Khan. 2004. "The Ayatollah and the transsexual," The Independent, November 25, World section.

Najmabadi, Afsaneh.2008 "Genus of Sex: Configurations of Sexuality and Gender in Twentieth-Century Iran.” Unpublished paper.

Najmabadi, Afsaneh. 2005. "Truth of Sex," Iranian.com, January 12, http://www.iranian.com/Najmabadi/2005/January/Sex/index.html.

Rofel, Lisa. 2007. Desiring China: Experiments in Neoliberalism, Sexuality, and Public Culture. Durham: Duke University Press.

Sanders, Paula. 1991. "Gendering the Ungendered Body: Hermaphrodites in Medieval Islamic Law." In Women in Middle Eastern History: Shifting boundaries in Sex and Gender, eds. Beth Baron and Nikki Keddie, 74-95. New Haven: Yale University Press. Stack, Megan K. 2005. “Changing Their Sexes in Iran,” Los Angeles Times, January 25. Tait, Robert. 2005. “A fatwa for freedom.” The Guardian, July 27, World News section. 